\title{
Multiplicação in vitro de Caesalpinia pyramidalis (Leguminosae)
}

\section{Tecla dos Santos Silva ${ }^{*}$, Cristina Ferreira Nepomuceno ${ }^{2}$, Bárbara Paula dos Santos Borges ${ }^{1}$, Bruno Freitas Matos Alvim ${ }^{1}$ \& José Raniere Ferreira de Santana ${ }^{1}$}

${ }^{1}$ Unidade Experimental Horto Florestal, Universidade Estadual de Feira de Santana, Feira de Santana, Bahia, Brasil.

${ }^{2}$ Universidade Federal do Recôncavo da Bahia, Cruz das Almas, Bahia, Brasil.

\begin{abstract}
Resumo - Caesalpinia pyramidalis é uma espécie endêmica da Caatinga, conhecida popularmente como catingueira, que possui ampla utilização pelas populações locais, principalmente por suas propriedades madeireiras, medicinais e forrageiras. Este trabalho objetivou estudar os efeitos dos tipos e concentrações de reguladores de crescimento vegetal sobre a multiplicação in vitro de C. pyramidalis. No primeiro experimento, segmentos nodais foram inoculados em meio contendo diferentes combinações $(0,0-8,0 \mu \mathrm{M})$ de BAP e de ANA. No segundo experimento, segmentos nodais foram inoculados em meio contendo diferentes tipos (KIN, BAP e TDZ) e diferentes concentrações $(0,0-16 \mu \mathrm{M})$ de citocininas. Utilizou-se o meio de cultura WPM suplementado com 87,64 mM de sacarose e solidificado com 7,0 $\mathrm{g} \mathrm{L}^{-1}$ de ágar. Após 45 dias registrou-se o maior número de brotos, número de folhas, comprimento da parte aérea e matéria seca da parte aérea em meio de cultura isento de regulador de crescimento vegetal.
\end{abstract}

Palavras-chave adicionais: cultivo in vitro, organogênese, reguladores de crescimento vegetal.

\begin{abstract}
In vitro multiplication of Caesalpinia pyramidalis (Leguminosae)) - Caesalpinia pyramidalis is a species endemic to the Caatinga and known popularly as catingueira, which is widely used by local people, mainly for its timber and medicinal and fodder properties. This study investigated the effects of different types and concentrations of plant growth regulators on the in vitro multiplication of $C$. pyramidalis. In the first experiment, nodal segments were inoculated in media containing different combinations $(0.0-8.0 \mu \mathrm{M})$ of BAP and NAA. In the second experiment, nodal segments were inoculated in media containing different types (KIN, BAP and TDZ) and concentrations (0.0$16 \mu \mathrm{M})$ of cytokinins. We used a WPM medium supplemented with $87.64 \mathrm{mM}$ sucrose and solidified with $7.0 \mathrm{~g} \mathrm{~L}^{-1}$ agar. After 45 days, the highest number of shoots, leaf number, shoot length and dry mass of shoots were obtained when nodal segments were inoculated into a culture medium without plant growth regulators.
\end{abstract}

Additional key words: in vitro culture, organogenesis, plant growth regulators.

Caesalpinia pyramidalis Tul. (Leguminosae) é uma árvore de porte médio, endêmica do sertão nordestino conhecida popularmente como catingueira, catinga-deporco ou pau-de-rato. A catingueira é bastante utilizada na medicina popular para o tratamento de febres, doenças estomacais, hepatite, anemia, infecções catarrais, diarreias e como diurético. Além de propriedades medicinais, a espécie possui potencial madeireiro e forrageiro para caprinos, ovinos e bovinos (Drumond et al. 2000), podendo ainda ser utilizada na fabricação de sabão (Maia 2004).

Em ambiente natural, sua propagação é feita por meio de sementes, que são produzidas apenas em um pequeno período do ano. Essa irregularidade aliada à má distribuição pluviométrica na região semiárida de um ano para outro, pode comprometer a obtenção de sementes, de tal forma que a maioria dos frutos apresenta sementes mal formadas ou inviáveis para a germinação (Matallo Júnior 2000; Oliveira et al. 2011). A exploração de sua madeira exige a extração da árvore, muitas vezes antes dela chegar à fase reprodutiva. Portanto, essa atividade pode impedir a reprodução natural da espécie e prejudicar sua

\footnotetext{
*Autora para correspondência: silva.stecla@gmail.com

Editor responsável: Alessandro Rapini

Submetido: 22 abr. 2013; aceito: 8 out. 2013

Publicação inicial: 30 dez. 2013; versão final: 2 maio 2014
}

propagação, podendo colocá-la sob risco de extinção. Dessa forma, existe uma pressão eminente voltada para o desenvolvimento de estratégias para sua multiplicação, conservação e manejo sustentável.

A utilização de recursos biotecnológicos, como técnicas de cultura de tecidos vegetais, tem auxiliado na propagação clonal de genótipos de várias espécies lenhosas, a exemplo de Bauhinia cheilantha (Bong.) Steud. (Gutiérrez et al. 2011), Caesalpinia echinata Lam. (Aragão et al. 2011), Plathymenia reticulata Benth. (Moura et al. 2012), Amburana acreana (Ducke) A.C.Sm. (Fermino Junior \& ScherwinskiPereira 2012), Amburana cearensis (Allemão) A.C. Sm. (Campos et al. 2013) e Tapirira guianensis Aubl. (Gutiérrez et al. 2013). A micropropagação constitui uma alternativa para a propagação de mudas sadias, em tempo e espaço físico reduzido, com alta fidelidade genética (George 2008). Nesse sentido, a utilização desta técnica da cultura de tecidos vegetais pode ser uma alternativa viável de propagação de Caesalpinia pyramidalis, visto que até o momento, não existem referências de trabalhos de micropropagação com a espécie.

$\mathrm{Na}$ obtenção dos processos morfogênicos in vitro, são utilizados reguladores de crescimento vegetal, como citocininas e auxinas. De acordo com Skoog \& Miller (1957), um balanço adequado entre auxinas e citocininas estabelece um controle eficiente no 
crescimento e na diferenciação das culturas in vitro. As citocininas são indispensáveis durante a fase de multiplicação, pois controlam a divisão celular e estão ligadas à diferenciação das células, sobretudo no processo de formação de gemas caulinares (Kerbauy 2008). Já as auxinas promovem divisão, alongamento e diferenciação celular, além de serem responsáveis pela dominância apical (Taiz \& Zeiger 2004).

Dentre as citocininas, o 6-benzilaminopurina (BAP), que tem sido a mais indicada para promover a proliferação de partes aéreas e indução de gemas adventícias in vitro (Grattaplaglia \& Machado 1998), é considerado eficiente na multiplicação de diversas espécies lenhosas. Outra citocinina bastante utilizada é a cinetina (KIN), seguida da fenilureia thidiazuron (TDZ), um composto sintético com atividade citocínica. Segundo Curti (2011), o TDZ surgiu como um regulador altamente eficaz em culturas de tecidos de um conjunto diversificado de espécies, que se estende desde gramíneas e herbáceas até espécies lenhosas.

Dentre as auxinas, o ácido naftalenoacético (ANA) é uma das mais empregadas em concentrações que variam conforme a espécie e/ou cultivar (Grattapaglia \& Machado 1998), sendo utilizada com êxito em combinações com outras citocininas na indução de brotos em várias espécies vegetais.

Dessa forma, o trabalho teve como objetivo estudar os efeitos do ANA combinado com o BAP e de tipos e concentrações de reguladores do grupo das citocininas na multiplicação in vitro de Caesalpinia pyramidalis, como estratégia alternativa para a exploração sustentável desse importante recurso genético, já que não existem relatos de métodos de propagação in vitro dessa espécie.

\section{MATERiAl e Métodos}

Os experimentos foram realizados no Laboratório de Cultura de Tecidos Vegetais (LCTV) da Unidade Experimental Horto Florestal (UNEHF), Universidade Estadual de Feira de Santana (UEFS), estado da Bahia. O meio de cultura utilizado em todos os ensaios foi o WPM (Lloyd \& McCown 1980), suplementado com $87,64 \mathrm{mM}$ de sacarose e solidificado com $7 \mathrm{~g} \mathrm{~L}^{-1} \mathrm{de}$ ágar (Himedia ${ }^{\circledR}$ ). $\mathrm{O}$ pH do meio de cultura foi ajustado para $5,7 \pm 0,1$, antes da autoclavagem, durante $15 \mathrm{~min}$. à temperatura de $121^{\circ} \mathrm{C}$ e pressão de 1 atm. Todas as culturas foram incubadas em sala de crescimento, mantidas com $60 \%$ de umidade relativa, temperatura de $25 \pm 2^{\circ} \mathrm{C}$, sob fotoperíodo de $16 \mathrm{~h}$ e uma densidade de fluxo de fótons de $60 \mu \mathrm{mol} \mathrm{m} \mathrm{m}^{-2} \mathrm{~s}^{-1}$, sendo que, logo após a inoculação, os tratamentos permaneceram no escuro por 5 dias a fim de evitar oxidações nos explantes. Para a obtenção dos explantes, sementes de Caesalpinia pyramidalis, coletadas no município de Retirolândia, Bahia, foram lavadas com água e detergente neutro, permanecendo em água corrente por $30 \mathrm{~min}$, sendo posteriormente imersas em solução do fungicida Derosal ${ }^{\circledR}\left(2 \mathrm{~mL} \cdot \mathrm{L}^{-1}\right)$ por $10 \mathrm{~min}$. Logo após, foram desinfestadas em álcool a 70\% (1 min), e hipoclorito de sódio (2,5\% de cloro ativo) com duas gotas de detergente neutro, por $15 \mathrm{~min}$. Em seguida, foram submetidas a lavagem por três vezes em água destilada estéril e inoculadas em tubos de ensaio contendo $10 \mathrm{~mL}$ de meio de cultura. Após 45 dias, foram utilizados segmentos nodais contendo uma gema axilar cada, os quais foram inoculados verticalmente em tubos de ensaio contendo $10 \mathrm{~mL}$ de meio de cultura acrescidos de reguladores de crescimento vegetal.

Experimento I: Efeito da interação da citocinina 6-benzilaminopurina (BAP) e da auxina ácido naftalenoacético (ANA). $O$ meio de cultura foi suplementado com diferentes concentrações de BAP $(0,0 ; 1,0 ; 2,0 ; 4,0$ e $8,0 \mu \mathrm{M})$ e ANA $(0,0 ; 1,0 ; 2,0 ; 4,0$ e $8,0 \mu \mathrm{M})$. O delineamento experimental utilizado foi inteiramente casualizado (DIC), em esquema fatorial $5 \times 5$ (concentrações de BAP $\times$ concentrações de ANA), totalizando 25 tratamentos constituídos por 10 repetições com quatro unidades experimentais (tubos de ensaio) cada.

Experimento II: Efeito de diferentes concentrações e tipos de citocininas. $O$ meio de cultura foi suplementado com diferentes concentrações e tipos de citocininas, constituindo os seguintes tratamentos: $0,0 \mu \mathrm{M}$ de citocinina; 2,0 $\mu \mathrm{M}$ de BAP; 4,0 $\mu \mathrm{M}$ de BAP; $8,0 \mu \mathrm{M}$ de BAP; 16,0 $\mu \mathrm{M}$ de BAP; 2,0 $\mu \mathrm{M}$ de $\mathrm{KIN} ; 4,0 \mu \mathrm{M}$ de $\mathrm{KIN} ; 8,0 \mu \mathrm{M}$ de $\mathrm{KIN} ; 16,0 \mu \mathrm{M}$ de $\mathrm{KIN} ; 1,0 \mu \mathrm{M}$ de TDZ; $2,0 \mu \mathrm{M}$ de TDZ; 4,0 $\mu \mathrm{M}$ de TDZ e 6,0 $\mu \mathrm{M}$ de TDZ. O experimento foi instalado em DIC, totalizando 13 tratamentos constituídos por 10 repetições com quatro unidades experimentais (tubos de ensaio) cada.

Variáveis e análise estatística. Após 45 dias da inoculação, foram avaliados o número de brotos e folhas e o comprimento e a matéria seca da parte aérea. Os dados foram analisados estatisticamente, mediante a análise de variância (ANOVA), e transformados pela função $(x+1)^{0,5}$. Quando o valor de " $F$ " foi significativo, as médias dos tratamentos qualitativos e ajustes foram submetidas ao teste de Tukey e as médias de tratamentos quantitativos foram submetidas à análise de regressão polinomial. São apresentadas as médias originais. As análises foram realizadas no programa SISVAR (Ferreira 2011).

\section{RESULTADOS}

Experimento I. A análise de variância revelou efeito altamente significativo $(p<0,01)$ da interação BAP $\times$ ANA para todas as variáveis estudadas. Ao avaliar o número de brotos verificou-se que a análise de regressão indicou modelo decrescente $(\mathrm{p}<0,01)$ das 
concentrações de ANA na ausência de BAP e quadrático $(\mathrm{p}<0,01)$ na presença de 2 e $8 \mu \mathrm{M}$ de BAP (Figura 1). O maior número de brotos $(0,97$ brotos/explante), número de folhas $(1,63)$, comprimento dos brotos $(17,90 \mathrm{~mm})$ e peso seco dos brotos $(5,77 \mathrm{mg})$ foi observado em meio de cultura isento de reguladores de crescimento vegetal (Figura 1).
Experimento II. A análise de variância revelou efeito altamente significativo $(\mathrm{p}<0,01)$ dos tratamentos testados para todas as variáveis analisadas. Para número de brotos observou-se uma redução nas médias à medida que houve aumento na concentração das citocininas no meio de cultura (Tabela 1). A maior média $(0,97$ broto/explante) observada para essa
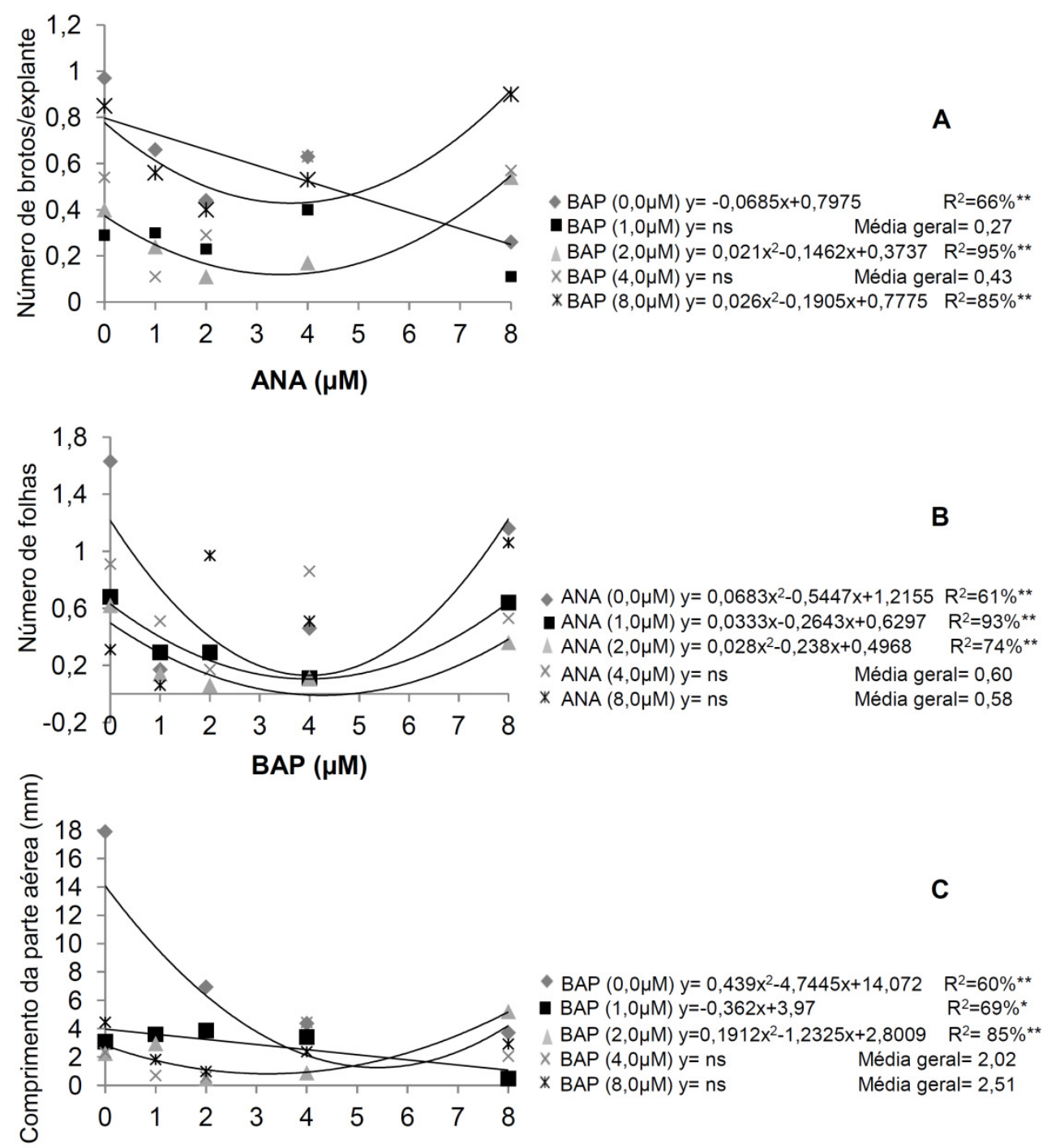

\section{C}

- BAP $(0,0 \mu M) y=0,439 x^{2}-4,7445 x+14,072 \quad R^{2}=60 \%$ ** - BAP $(1,0 \mu M) y=-0,362 x+3,97 \quad R^{2}=69 \% *$ BAP $(2,0 \mu M) y=0,1912 x^{2}-1,2325 x+2,8009 \quad R^{2}=85 \%^{* *}$ $\times \operatorname{BAP}(4,0 \mu \mathrm{M}) \mathrm{y}=\mathrm{ns} \quad$ Média geral $=2,02$ * BAP $(8,0 \mu M) y=n s \quad$ Média geral $=2,51$

ANA $(\mu \mathrm{M})$

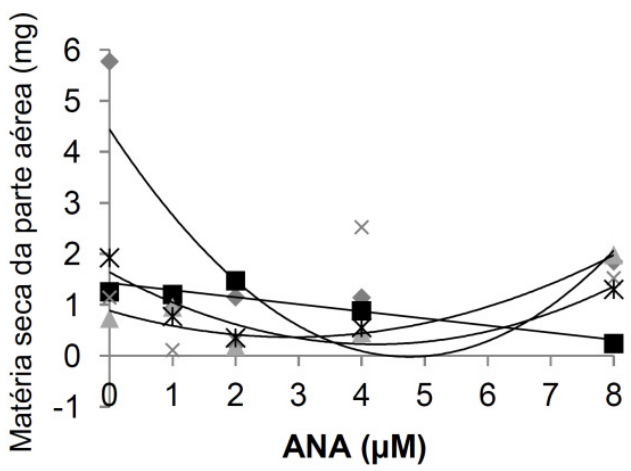

D

BAP $(0,0 \mu M) y=0,1976 x^{2}-1,8776 x+4,4403 \quad R^{2}=62 \%$ ** - $\operatorname{BAP}(1,0 \mu \mathrm{M}) \mathrm{y}=-0,1385 x+1,4235 \quad \mathrm{R}^{2}=84 \%$ * $\triangle \operatorname{BAP}(2,0 \mu \mathrm{M}) \mathrm{y}=0,0618 x^{2}-0,3581 x+0,8837 \quad R^{2}=89 \% *$ $x \operatorname{BAP}(4,0 \mu \mathrm{M}) \mathrm{y}=\mathrm{ns} \quad$ Média geral $=1,12$ * $\operatorname{BAP}(8,0 \mu \mathrm{M}) \mathrm{y}=0,0794 \mathrm{x}^{2}-0,6697 x+1,638 \quad \mathrm{R}^{2}=79 \%$ **

Figura 1. Número de brotos (A), número de folhas (B), comprimento da parte aérea (C) e matéria seca da parte aérea (D) obtidos a partir de segmento nodal de C. pyramidalis, aos 45 dias em meio de cultura suplementado com diferentes concentrações de 6-benzilaminopurina (BAP) e ácido naftalenoacético (ANA). **significativo com $1 \%$ de probabilidade pelo teste $\mathrm{F} ;$ *significativo com $5 \%$ pelo teste $\mathrm{F}$; ${ }^{\text {ns }}$ Não significativo ao nível de 5\% pelo teste F. Feira de Santana, BA. 2013. 
Tabela 1. Médias do número de brotos (NB), número de folhas (NF), comprimento da parte aérea (CPA) e matéria seca da parte aérea (MSPA) obtidas a partir de segmento nodal de C. pyramidalis, aos 45 dias com diferentes concentrações e tipos de citocininas (BAP- 6benzilaminopurina; KIN- cinetina; TDZ- thidiazuron). Feira de Santana, Bahia, 2013.

\begin{tabular}{|c|c|c|c|c|}
\hline Tratamento & NB & NF & CPA (mm) & MSPA (mg) \\
\hline $0,0 \mu \mathrm{M}$ de citocinina & $0,97^{\mathrm{a}}$ & $1,63^{\mathrm{a}}$ & $17,90^{\mathrm{a}}$ & $5,77^{\mathrm{a}}$ \\
\hline $2,0 \mu \mathrm{M}$ de BAP & $0,40^{\mathrm{bc}}$ & $0,29^{\text {bcd }}$ & $2,26^{\mathrm{b}}$ & $0,73^{\mathrm{b}}$ \\
\hline $4,0 \mu \mathrm{M}$ de BAP & $0,54^{\mathrm{b}}$ & $0,46^{\mathrm{bc}}$ & $2,31^{b}$ & $1,14^{\mathrm{b}}$ \\
\hline $8,0 \mu \mathrm{M}$ de BAP & $0,24^{\text {cdef }}$ & $0,38^{\text {bed }}$ & $2,09^{\mathrm{b}}$ & $0,63^{\mathrm{b}}$ \\
\hline $16,0 \mu \mathrm{M}$ de BAP & $0,16^{\text {cdef }}$ & $0,20^{\mathrm{bcd}}$ & $0,96^{\mathrm{b}}$ & $0,98^{\mathrm{b}}$ \\
\hline $2,0 \mu \mathrm{M}$ de $\mathrm{KIN}$ & $0,24^{\text {cdef }}$ & $0,23^{\mathrm{bcd}}$ & $1,69^{\mathrm{b}}$ & $0,19^{\mathrm{b}}$ \\
\hline $4,0 \mu \mathrm{M}$ de $\mathrm{KIN}$ & $0,38^{\text {bcd }}$ & $0,49^{\mathrm{b}}$ & $2,57^{\mathrm{b}}$ & $0,74^{\mathrm{b}}$ \\
\hline $8,0 \mu \mathrm{M}$ de $\mathrm{KIN}$ & $0,17^{\text {cdef }}$ & $0,23^{\mathrm{bcd}}$ & $0,62^{\mathrm{b}}$ & $0,45^{\mathrm{b}}$ \\
\hline $16,0 \mu \mathrm{M}$ de $\mathrm{KIN}$ & $0,27^{\text {cde }}$ & $0,39^{\text {bcd }}$ & $0,81^{\mathrm{b}}$ & $0,22^{\mathrm{b}}$ \\
\hline $1,0 \mu \mathrm{M}$ de TDZ & $0,15^{\mathrm{ef}}$ & $0,15^{\mathrm{bcd}}$ & $0,86^{\mathrm{b}}$ & $0,46^{\mathrm{b}}$ \\
\hline $2,0 \mu \mathrm{M}$ de TDZ & $0,04^{\mathrm{ef}}$ & $0,04^{\text {cd }}$ & $0,14^{\mathrm{b}}$ & $0,13^{\mathrm{b}}$ \\
\hline $4,0 \mu \mathrm{M}$ de TDZ & $0,00^{\mathrm{f}}$ & $0,00^{\mathrm{d}}$ & $0,00^{\mathrm{b}}$ & $0,00^{\mathrm{b}}$ \\
\hline $6,0 \mu \mathrm{M}$ deTDZ & $0,00^{\mathrm{f}}$ & $0,00^{\mathrm{d}}$ & $0,00^{\mathrm{b}}$ & $0,00^{\mathrm{b}}$ \\
\hline
\end{tabular}

Médias seguidas pela mesma letra na coluna não diferem estatisticamente no nível de 5\% pelo teste Tukey.

variável foi alcançada na ausência dos reguladores de crescimento vegetal. Sendo que na utilização de concentrações maiores da citocinina TDZ (4 $\mu \mathrm{M}$ e $6 \mu \mathrm{M})$ foram encontrados os piores resultados, não havendo formação de brotos (Tabela 1). Comportamento similar foi obtido também para o número de folhas, comprimento e matéria seca da parte aérea, cujas maiores médias foram registradas na ausência das citocininas e os piores resultados nas maiores concentrações de TDZ testadas (Tabela 1).

Ao avaliar os tratamentos contendo a citocinina BAP ou KIN, verificou-se uma queda significativa no número de brotos à medida que se aumentaram as concentrações dessas citocininas, sendo que, ao comparar-se o meio de cultura suplementado com BAP e KIN, as maiores médias para número de brotos foram observadas com o segmento nodal em meio incrementado com BAP ao invés de KIN (Tabela 1). Finalmente, pôde-se observar a formação de calo na base ou na parte caulinar dos explantes com a adição de concentrações maiores de citocininas (dados não mostrados).

\section{DiscuSSÃo}

Experimento I. A utilização de reguladores de crescimento vegetal no meio de cultura nas concentrações testadas não se mostraram satisfatórias para a indução de brotações em catingueira, visto que o maior número de brotos foi observado em meio de cultura sem reguladores. O comportamento observado para a espécie pode ser atribuído às características que os reguladores de crescimento vegetal possuem de inibir, promover ou modificar as diferentes respostas fisiológicas, mesmo em baixas concentrações, através das quais controlam o crescimento e desenvolvimento da planta (Vieira et al. 2010). As concentrações dos reguladores de crescimento vegetal utilizadas aqui provavelmente não foram suficientes para promover a proliferação dos brotos a partir dos tecidos meristemáticos das gemas axilares. De acordo com Peres (2002), a obtenção de organogênese in vitro é um processo empírico onde são testados, para cada espécie ou mesmo para cada variedade dentro de uma espécie, a fonte de explante, composição mineral do meio de cultura, balanço hormonal e condições ambientais. $\mathrm{O}$ mesmo autor ainda destaca que os componentes mais críticos adicionados ao meio de cultura são os reguladores de crescimento vegetal. Dessa forma, o balanço hormonal entre concentrações de citocininas e auxinas endógenas e exógenas é um fator de suma importância para o sucesso em sistemas de micropropagação, nos quais objetivam-se altas taxas de multiplicação. No presente estudo, esse balanço hormonal não deve ter sido atingido.

A baixa taxa de multiplicação observada para catingueira corrobora Flôres et al. (2011), que também obtiveram o maior número de brotações por explante $(1,6)$ em culturas de Luehea divaricata Mart. quando o meio estava isento de reguladores de crescimento vegetal. $\mathrm{O}$ comportamento observado para número de brotos refletiu-se diretamente no número de folhas, que é uma variável de grande relevância em trabalhos de propagação in vitro durante a fase de multiplicação, pois na inserção entre o caule e a folha existe a produção de gema, a qual poderá dar origem a um novo broto e, consequentemente, aumentar a produção de novas mudas (Costa et al. 2010). No entanto, para a catingueira foi verificado baixo número de folhas, discordando assim de Costa et al. (2010) que observaram efeito linear crescente para o número de folhas de Erythrina velutina Willd., alcançando uma média de 9,4 folhas em meio de cultura suplementado com 17,76 $\mu \mathrm{M}$ de BAP combinado com 1,34 $\mu \mathrm{M}$ de ANA. 
O maior comprimento dos brotos observados na ausência dos reguladores de crescimento vegetal corrobora Kang et al. (2009), que também registraram o maior comprimento dos brotos de Populus trichocarpa Torr. \& A. Gray em meio isento de reguladores de crescimento vegetal. O declínio observado na altura dos brotos com a adição de reguladores de crescimento vegetal pode ser associado ao fato de que as citocininas controlam a divisão celular, estando intimamente ligadas à diferenciação das células e sobretudo na formação de gemas caulinares (Kerbauy 2008), atuando também na quebra da dominância apical, o que leva a uma redução no tamanho das plantas. Dessa forma, à medida que se reduz as concentrações das citocininas, há um aumento no comprimento da parte aérea de Caesalpinia pyramidalis. $\mathrm{O}$ maior valor médio para matéria seca foi registrado então na ausência de reguladores de crescimento vegetal, o que pode ser explicado pela influência direta do comprimento dos brotos no peso seco, visto que os maiores brotos tendem a pesar mais.

Experimento II. Houve uma queda significativa nas médias de todas as variáveis analisadas com a adição das citocininas no meio de cultura, sendo que os piores resultados foram observados com as concentrações mais altas de TDZ. O thidiazuron é um potente regulador de crescimento que faz parte do grupo das fenilureias, não possuindo o anel purina das citocininas como benzilaminopurina e cinetina, sendo utilizado para induzir brotações em várias espécies lenhosas (Mok et al. 1987; Lu 1993). Esse regulador possui alta atividade citocínica, de forma que concentrações menores em relação às outras citocininas geralmente favorecem resultados melhores na indução de brotos. Segundo Ribeiro et al. (2010), o TDZ é mais ativo na multiplicação que outras citocininas por causa do aumento da atividade da fosfatase ácida. Essa enzima promove a interconversão nucleotídeonucleosídeo da estrutura de citocininas endógenas, tornando-as biologicamente mais ativas, podendo manifestar-se como inibidor do crescimento quando utilizado na mesma concentração de outras citocininas. Tais características podem explicar os piores resultados na utilização das concentrações mais altas dessa citocinina. No entanto, a utilização do TDZ, mesmo nas menores concentrações, não foi eficiente na multiplicação in vitro da catingueira. Diferente do que foi observado neste estudo, no entanto, espécies lenhosas como Rauvolfia tetraphylla L. e Leucaena leucocephala (Lam.) de Wit apresentaram um alto número de brotos com a utilização de 5,0 (9,2 brotos/explante) e $0,23 \mu \mathrm{M}$ (6,98 brotos/explante) de TDZ, respectivamente, adicionado ao meio de cultura (Faisal et al. 2005; Shaik et al. 2009).

As maiores médias para todas as variáveis analisadas obtidas com BAP em relação à KIN, quando foram comparados os tratamentos contendo apenas essas citocininas, podem ser atribuídas à influência deste regulador de crescimento vegetal na divisão celular e na liberação das gemas axilares inibidas pela dominância apical, sendo ainda esta citocinina muito eficaz para promover a multiplicação em diversas espécies lenhosas (Cordeiro et al. 2004). No entanto, para a catingueira, a presença de BAP no meio de cultura não se mostrou eficiente para a proliferação de brotos, sendo registrado um declínio significativo para taxa de multiplicação dos explantes à medida que se adicionou esta citocinina ao meio de cultura. De acordo com Schuch \& Erig (2005), as concentrações de citocininas para a multiplicação in vitro estão entre 0,44 e 22,2 $\mu \mathrm{M}$. Esses resultados indicam que é necessário testar outras citocininas e outras concentrações delas a fim de se estabelecer um balanço hormonal interno que aumente o número de brotos formados.

A baixa taxa de multiplicação in vitro encontrada para Caesalpinia pyramidalis corrobora os resultados observados em várias espécies lenhosas, como Luehea divaricata com 1,6 brotos/explantes (Flôres et al. 2011), Cabralea canjerana (Vell.) Mart. com 1,66 brotos/explante (Rocha et al. 2007) e Schizolobium amazonicum Huber ex Duck com 2,14 brotos/explante (Cordeiro et al. 2004).

A formação de calo na base dos explantes de catingueira com adição das maiores concentrações de citocininas também foi observada em culturas de outras espécies lenhosas como Hancornia speciosa, Erythrina velutina, e Caesalpinia echinata (Soares et al. 2007; Costa 2009; Aragão et al. 2011). Para que ocorra a formação de brotos é necessário que, no balanço auxinas $\times$ citocininas, as concentrações de citocininas se sobressaiam. Para ocorrer a calogênese, deve haver uma equilíbrio no balanço hormonal (Guerra \& Nodari 2006), visto ainda que o balanço entre as quantidades de citocininas exógenas e auxinas endógenas variam conforme o tecido utilizado como explante (Brunetta et al. 2006). Dessa forma os resultados encontrados para a catingueira são explicados provavelmente pelo desbalanço hormonal, produzindo calo.

Este trabalho relata pela primeira vez a multiplicação in vitro de Caesalpinia pyramidalis. Baseados nesses resultados conclui-se que os reguladores de crescimento vegetal nas concentrações testadas não foram eficientes para promover a indução de brotos em segmentos nodais. Dessa forma, sugerese a realização de estudos utilizando outras fontes de explante ou vias de regeneração para aumentar as taxas de multiplicação.

\section{REFERÊNCIAS}

Aragão, A.K.O.; Aloufa, M.A.I \& Costa, L.A. 2011. Efeito do BAP (6-Benzilaminopurina) sobre a indução de brotos em explantes de pau-brasil. Cerne 17: 339-345.

Brunetta, J.M.F.C.; Otoni, W.C.; Pinheiro, A.L. \& Fonseca, E.P. 2006. Calogênese in vitro em segmentos de epicótilo de 
mogno (Swietenia macrophylla King) com uso de 6benzilaminopurina e ácido $\alpha$-naftalenoacético. Scientia Forestalis 71: 19-24.

Campos, V.C.A.; Lima-Brito, A.; Gutierrez, I.E.M.; Santana, J.R.F. \& Souza, A.V.V. 2013. Micropropagação de umburana de cheiro. Ciência Rural 43: 639-644.

Cordeiro, I.M.C.C.; Lameira, O.A.; Ohashi, S.T. \& Rosal, L.F. 2004. Efeito de BAP sobre a proliferação de brotos in vitro de Schizolobium amazonicum Huber ex Ducke (Paricá). Cerne 10: 118-124.

Costa, G.M. 2009. Propagação In Vitro de Erythrina velutina. Dissertação de Mestrado. Programa de Pós Graduação em Biotecnologia, Universidade Estadual de Feira de Santana, Feira de Santana.

Costa, G.M.; Nepomuceno, C.F. \& Santana, J.R.F. 2010 Propagação in vitro de Erythrina velutina. Ciência Rural 40: 1090-1096.

Curti, A.R. 2011. Contribuições para a Micropropagação de Peltophorum dubium (SPRENGEL) Taubert. - Dissertação de Mestrado. Programa de Pós-graduação em Engenharia Florestal, Universidade Federal de Santa Maria, Santa Maria.

Drumond, M.A.; Kiill, L.H.P.; Lima, P.C.F.; Oliveira, M.C.; Oliveira, V.R.; Albuquerque, S.G.; Nascimento, C.E.S. \& Cavalcanti, J. 2000. Avaliação e Identificação de Ações Prioritárias para a Conservação, Utilização Sustentável e Repartição de Beneficios da Biodiversidade do Bioma Caatinga: estratégias para o uso sustentável da biodiversidade da Caatinga, Petrolina. Disponível em: <http://www. semiarido.org.br/UserFiles/file/Estrategias\%20para\%20uso\%20 sustentavel\%20da\%20caatinga.pdf $>$ Acesso em: 4 de agosto de 2011.

Faisal, M.; Ahmad, N. \& Anis, M. 2005. Shoot multiplication in Rauvolfia tetraphylla L. using thidiazuron. Plant Cell, Tissue and Organ Culture 80: 187-190.

Fermino Junior, P.C.P. \& Scherwinski-Pereira, J.E. 2012 Germinação e propagação in vitro de cerejeira (Amburana acreana (Ducke) A.C. Smith - Fabaceae). Ciência Florestal 22: $1-9$.

Ferreira, D.F. 2011. Sisvar: a computer statistical analysis system. Ciência e Agrotecnologia 35: 1039-1042.

Flôres, A.V.; Reiniger, L.R.S.; Curti, A.R.; Cunha, A.C.M.C.M;. Golle, D.P. \& Bassan, J.S. 2011 Estabelecimento e multiplicação in vitro de Luehea divaricata Mart \& Zucc. Ciência Florestal 21: 175-182.

George, E.F. 2008. Plant Tissue Culture Procedure - Background In: E.F George, M.A Hall \& G-J Klerk (eds), Plant Propagation by Tissue Culture: the background. Vol. 1. 3.ed., Springer, Dordrecht, p. 2-28.

Grattapaglia, D \& Machado, M.A. 1998. Micropropagação. In: A.C. Torres, L.S Caldas \& J.A. BUSO (eds), Cultura de Tecidos e Transformação Genética de Plantas. Vol. 1 Embrapa - SPI / Embrapa - CNPH, Brasília.

Guerra, M. P \& Nodari, R.O. 2006. Apostila de biotecnologia. Florianópolis: Steinmacher. disponível em $<$ http://www.lfdgv.ufsc.br/Apostila\%20Biotecnologia.pdf $>$. Acesso em 15 de agosto de 2011.

Gutiérrez, I.E.M.; Nepomuceno, C.F.; Ledo, C.A.S. \& Santana, J.R. 2011. Regeneração in vitro via organogênese direta de Bauhinia cheilantha. Ciência Rural 41: 260-265.

Gutiérrez, I.E.M.; Nepomuceno, C.F.; Silva, T.S.; Fonseca, P.T.; Campos, V.C.A; Alvim, B.F.M.; Carneiro. F.S.; Albuquerque, M.M.S. \& Santana, J.R.F. 2013. Multiplicação in vitro de Tapirira guianensis Aubl. (Anacardiaceae). Revista Ceres 60: 143-151.
Kang, B.; Osburn, L.; Kopsell, D.; Tuskan, G.A. \& Cheng, Z.M. 2009. Micropropagation of Populus trichocarpa 'Nisqually-1': the genotype deriving the Populus reference genome. Plant Cell Tissue Organ Culture 99: 251-257.

Kerbauy, G.B. 2008. Fisiologia Vegetal. 2 ed. Guanabara Koogan, Rio de Janeiro.

Lloyd, G \& McCown, B. 1980. Use of microculture for production and improvement of Rhododendron spp. HortScience 15: 416420.

Lu, C. 1993. The use of thidiazuron in tissue culture. In vitro Cellular \& Developmental Biology 29: 92-96.

Maia, G. N. 2004. Caatinga: árvores e arbustos e suas utilidades. Leitura \& Arte, São Paulo.

Matallo Júnior, H.A. 2000. Desertificação no Brasil. In: T.S. Oliveira, R.N. Assis Jr., R.E. Romero e J.R.C. Silva (eds), Agricultura, Sustentabilidade e o Semi-árido. UFC, Fortaleza, p. $89-113$.

Mok, M. C.; Mok, D.; Turner, J. \& Mujer, C. 1987. Biological and biochemical effects of cytokinin-active phenylurea derivatives in tissue culture systems. HortScience 22: 1194197.

Moura, L.C.; Titon, M.; Miranda, N.A.; Moreira, T.P. \& Oliveira, M.L.R. 2012. Multiplicação e alongamento in vitro de vinhático (Plathymenia reticulata). Scientia Forestalis 40: 499-505.

Oliveira, L.M.; Bruno, R.L.A.; Silva, K.R.G.; Alves, E.U.; Silva, G.Z. \& Andrade, A.P. 2011. Qualidade fisiológica de sementes de Caesalpinia pyramidalis Tul. durante o armazenamento. Revista Brasileira de Sementes 33: 289-298.

Peres, L.E.P. 2002. Bases fisiológicas e genéticas da regeneração de plantas in vitro. Biotecnologia Ciência \& Desenvolvimento 25: 44-48.

Ribeiro, C.S.N.; Silva, H.; Santos, J.W. \& Carvalho, J.M.F.C. 2010. Efeito do tiadiazuron na micropropagação in vitro de dois genótipos de mamona via organogênese. Revista Brasileira de Engenharia Agrícola e Ambiental, 14: p.366-371.

Rocha, S.C.; Quorim, M.; Ribas, L.L.P. \& Koehler, H.S. 2007. Micropropagação de Cabralea canjerana. Revista Árvore 31: 43-50.

Schuch, M.W. \& A.C Erig. 2005. Micropropagação de plantas frutíferas. In: J.C. Fachinello, A. Hoffmann \& J.C Nachtigal. Propagação de Plantas Frutíferas. Embrapa Informação Tecnológica, Brasília, p. 155-173.

Shaik, N.M.; Arha, M.; Nookaraju, A.; Gupta, S.K.; Srivastava, S.; Yadav, A.K.; Kulkarni, P.S.; Abhilash, O.U.; Vishwakarma, R.K.; Singh, S.; Tatkare, R.; Chinnathambi, K.; Rawal, S. \& Khan, B.M. 2009. Improved method of in vitro regeneration in Leucaena leucocephala - a leguminous pulpwood tree species. Physiology and Molecular Biology of Plant 15: 311-318.

Skoog, F. \& Miller, C.O. 1957. Chemical Regulation of Growth and Organ Formation in Plant Tissues Cultured In Vitro. XI Symposium of the Society of Experimental Biology. Cambridge University Press, Cambridge, p. 118-131.

Soares, F.P.; Paiva, R.; Alvarenga, A.A.; Nogueira, R.C.; Emrich, E.B. \& Martinotto, C. 2007. Organogênese direta em explantes caulinares de mangabeira (Hancornia speciosa Gomes). Ciência e Agrotecnologia 31: 1048-1053.

Taiz, L.\& Zeiger, E. 2004. Fisiologia Vegetal. 3. ed. Artmed, Porto Alegre.

Vieira, E.L.; Souza, G.S.; Santos, A.R. \& Silva, J.S. 2010. Manual de Fisiolgia Vegetal. EDFMA, São Luis. 